\title{
A Comparative Synthesis of UK Mathematics Education Research: what are we talking about and do we align with international discourse?
}

Rachel Marks ${ }^{\mathrm{a} *}$, Colin Foster ${ }^{\mathrm{b}}$, Nancy Barclay ${ }^{\mathrm{a}}$, Alison Barnes ${ }^{\mathrm{a}}$, and Páraic Treacy $^{\mathrm{a}}$

${ }^{a}$ School of Education, University of Brighton, Brighton, UK; ${ }^{b}$ Mathematics Education Centre, Loughborough University, Loughborough, UK

*corresponding author: Dr Rachel Marks, Principal Lecturer in Mathematics Education, School of Education, University of Brighton, Checkland Building, Village Way, Falmer, BN1 9PH, Email: r.g.marks@brighton.ac.uk https://orcid.org/0000-0003-01042184 


\title{
A Comparative Synthesis of UK Mathematics Education Research: what are we talking about and do we align with international discourse?
}

\author{
This paper makes an important and original contribution to the updating of \\ methodological approaches to research syntheses. We analysed all 813 \\ Proceedings of the British Society for Research into Learning Mathematics from \\ 2003 to 2018 , first using a quantitative corpus-survey and qualitative thematic \\ coding and, again, independently, using topic modelling. We found strong \\ convergence between findings from the different methods. We compare our \\ findings to those from an earlier Proceedings review (1995-2002) and to a recent \\ review of the corpus of publications in the Journal for Research in Mathematics \\ Education and Educational Studies in Mathematics, as well as to a review by the \\ European Society for Research into Learning Mathematics and several other \\ reviews. We found considerable similarity between the issues discussed, and \\ similar trends over time. We conclude that the efficiency of topic modelling \\ makes it a powerful option to include among a range of methodological \\ approaches to research review.
}

Keywords: mathematics education review; mixed methods; topic modelling

\section{Introduction}

The field of mathematics education has developed considerably over the last 50 years, from what Schoenfeld (2016) called "an orphan discipline, with neither an identity nor a home" (p. 505) to what he recently termed a strong discipline in its own right. There are now numerous journals with an explicit focus on mathematics education (Nivens \& Otten [2017] recently identified 69) and, along with professional journals, conference papers and grey literature, this represents an enormous quantity of information. As Dreyfus, Artigue, Potari, Prediger and Ruthven (2018) remarked, "nowadays it is increasingly hard for researchers even to read all the relevant work that has been published on their topic, let alone to take comprehensive account of it in conducting and 
reporting their own research" (p. xx). Naturally, they call, as others have done previously (e.g. Yore \& Lerman, 2008), for syntheses of this corpus to help researchers take stock and move the field forwards. However, carrying out this work using the traditional qualitative methods of reading all of the literature and coding by hand is highly labour-intensive.

Numerous reviews of mathematics education research have been carried out, mostly adopting largely qualitative approaches and restricting the sample of articles as necessary in order to make the task manageable. In contrast to this, Inglis and Foster (2018) recently used a method from computational linguistics called topic modelling (Blei, $\mathrm{Ng}, \&$ Jordan, 2003) to analyse the entire corpus of nearly 4000 articles published in the Journal for Research in Mathematics Education (JRME) and Educational Studies in Mathematics (ESM) over the last 50 years. This approach does not require the articles to be read by a human being; indeed, far from being problematic, the larger the number of articles the better for the accuracy of the algorithm. The method operates by modelling the co-occurrence of individual words and offers an objective way to derive topics from an unstructured set of documents (although the naming of the topics obtained from the model is done using human judgment). However, this objectivity raises the question of the validity of the approach and the extent to which the results of a topic modelling (TM) analysis would align with those from a more traditional, qualitative analysis. A recent review of TM (Eickhoff \& Neuss, 2017) found growing use of the method across a range of disciplines, but called for more research validating the results from the topic models obtained.

In this paper, we report two independent analyses of the full corpus of the British Society for Research into Learning Mathematics (BSRLM) conference Proceedings from 2003 to 2018, one using a corpus-survey/qualitative thematic coding 
approach, and the other using TM, and compare the outcomes to examine the extent to which the conclusions obtained differ. Our three research questions for this paper are: (1) What are the main topics that appear within these Proceedings and how has their prevalence changed over time? (2) To what extent do these topics and their trends align with mathematics education research discourse internationally? and (3) How similar or different are the findings obtained from the two independent analyses (corpussurvey/qualitative thematic coding and topic modelling)?

BSRLM is the major society in the UK for academics and practitioners interested in research in mathematics education, and holds three Day Conferences each year. Between 2003 and 2018, BSRLM held 48 such conferences, leading to the publication of the 813 Proceedings considered within this synthesis. This synthesis follows on from an earlier synthesis (Nickson, 2003), which surveyed the Proceedings from 1995-2002. This current synthesis comes as the editors of Research in Mathematics Education (RME) celebrate 21 years of the journal (Jones, Black \& Coles, 2019) and its continued relationship with BSRLM. In contrast to reviews focused on journal articles, here we analyse Proceedings - edited, but not peer-reviewed. This focus on studies conducted but not (yet) formally written up for peer-reviewed journals, and carried out sometimes by teacher-researchers or less senior academics, may provide a sense of smaller, unfunded pieces of work, as well as including the reporting of early stages of larger studies. We intend that studying the content of the BSRLM Proceedings will give insight into the recent interests of a broad section of researchers in mathematics education in the UK.

\section{Method}

During 2018, we conducted for BSRLM a survey and qualitative thematic review of the full corpus of 773 conference Proceedings from 2003 to 2017 (Marks, Barclay, Barnes 
$\&$ Treacy, 2019). For this paper, we updated the dataset to include the Proceedings from 2018 when they became available. In 2019, following the publication of Inglis and Foster (2018), and with an interest in comparing methodological approaches to synthesis, we subsequently, and independently, used a topic modelling approach to replicate the review with the same corpus. Here, we present and compare the findings from both approaches.

\section{Corpus survey and thematic review}

For the 2003-2017 corpus survey (773 Proceedings), we constructed a database capturing title, author(s), keywords, study country, paper type (e.g. literature review or empirical study), methodological approach, phase, study population, and data-collection and analysis methods. Based on scrutiny of the full publication, each Proceeding was coded by one of the authors. Weekly discussions and cross-coding were conducted, ensuring that each coder completed the database reliably and consistently. Keywords were assigned by coders when none were present (including all of the Proceedings from 2003 up to and including March 2008) or when the keywords assigned were not suitable or useful (e.g. instances when 'mathematics education' was listed as a keyword). In total, 174 different keywords were applied, and we grouped these into 14 keywordgroups, based on our perceptions of the field. For example, the keyword-group of Assessment and Accountability contained the keywords: ability; accountability; assessment; attainment; formative assessment; gifted; performativity; coursework; student analysis and tests. Each of the Proceedings was typically assigned to multiple keyword-groups. We calculated descriptive statistics for each pertinent characteristic (e.g. frequency of empirical study, literature review or theoretical paper under paper type) and used these and Pearson's $r$ to explore potential changes in characteristics over the review period. For this paper, data from the 2018 Proceedings were subsequently 
captured and added to the database and the statistical analyses re-run. The keywordgroups, alongside the findings from the statistical analysis, informed the areas that we explored within the qualitative analysis. The researchers' tracking of narratives which developed through connected reports of research within the Proceedings also played a role in the identification of key areas.

\section{Topic Modelling}

For the subsequent, independent, Topic Modelling (TM) analysis (Blei, Ng, \& Jordan, 2003), we manually deleted from all of the 2003-2018 pdf files any 'noncontent', such as copyright statements, and then converted the files to plain text using pdftotext $^{1}$ (an open-source command-line utility). We sense-checked the output of all files and removed 11 files (all from 2004 Issue 3) which contained content that was corrupted, and could not be converted to text from the original pdf files, and hence our final data set for the Topic Modelling consisted of 802 files (994,731 words). We used MALLET (Version 2.0.8RC2), a UNIX command-line topic-modelling tool (McCallum, 2002), to calculate possible topic models, first removing 'stop words' - common English words, such as 'the', 'is', and 'a' - on MALLET's default list. Inspection of the perplexity graph (Figure 1) suggested that 25 to 35 topics would be a reasonable number to model, and a piecewise regression confirmed this, so we generated topic models for 25, 30 and 35 topics.

\section{INSERT FIGURE 1 NEAR HERE}

We interpreted the topics identified by the algorithm in two stages. Initially, we studied the word lists generated as highly characteristic of each topic. For instance, the

\footnotetext{
${ }^{1}$ https://www.xpdfreader.com/pdftotext-man.html
} 
words with the highest probabilities in the first topic identified were: pupils, answer, number, question, correct, strategies, questions, answers, method, strategy, children, calculation, methods, understanding, numbers, addition, research, year, study, incorrect. From these, it seemed clear that the topic was concerned with calculation, so we named this topic Calculation. The second stage involved studying those Proceedings that had high proportions of the included words. For instance, the Proceeding with the highest proportion of words from the Calculation topic (78\%, excluding stop words) was Borthwick and Harcourt-Heath's (2007) Proceeding, looking at the calculation strategies used by Year 5 (ages 10-11) children. Studying the 10 Proceedings with the highest proportions of words from each topic enabled us to understand the nature of the generated topics further and either supported our original naming from the word lists or helped us to refine this. For example, the topic we eventually named 'Storying experiences in mathematics education' seemed problematic from inspecting the word list, as there was no apparent theme linking the words. However, inspection of the Proceedings that had the highest proportions of the included words revealed a commonality in their methodological approach: all of them took a storying or narrative approach to the generation and/or communication of the data underlying the research, allowing us to generate the name 'Storying experiences in mathematics education', which seemed a good fit for the topic.

The topic naming process was repeated by another author for all of the topics generated within each $(25 / 30 / 35)$ model. We found that the overall message from the data was not sensitive to varying the number of topics from 25 to 30 to 35 , and here we present the 30-topics model, which had the fewest hard-to-interpret topics. The topics in the 30-topic model were then named independently by another researcher. Initial interrater agreement was $87 \%$, with no serious disagreements, and minor differences were 
resolved following discussion. Trends over the time period were examined graphically for each of the 30 generated topics and Pearson's $r$ was calculated to describe the linear correlation.

\section{Results and discussion}

We first address research question 3 , about how similar or different the findings are from the two independent analyses (corpus-survey/qualitative thematic coding and topic modelling). We then address research questions 1 and 2 by summarising the themes and trends obtained and compare these with those found in previous reviews.

\section{Comparison of methods}

Table 1 lists the 14 keyword-groups identified within the survey in order of frequency and maps the topics generated from the TM onto these. For each keyword-group, the most commonly occurring keywords are given, and, for each of the topics, the top 20 characteristic words from the TM are given in order of frequency. Pearson's $r$ for each of the topics with year is included, to give a general indication of trend over time, although many of these were highly non-linear, as can be seen from the trend graphs shown in Figure 2.

\section{INSERT TABLE 1 NEAR HERE \\ INSERT FIGURE 2 NEAR HERE}

Table 1 makes clear the strong similarity between the results from both methods. All topics mapped onto the keyword-groups, and the trends within each topic aligned closely with the findings from the survey. For example, 'teachers' emerged as the most prevalent keyword-group in the survey (i.e., this keyword-group had the largest number of Proceedings attached to it), with the most common keywords here being initial teacher training (ITT), teacher subject knowledge, and professional learning. This is 
closely aligned to the TM topics of preservice teacher education, teachers' subject knowledge and teacher collaborative research and CPD (see Table 1).

Occasionally, a survey keyword-group had no corresponding TM topic. The Survey identified areas covered both strongly and less strongly, but TM generates only the strongest topics. Affect and cognition appear in the Survey without mapped TM topics. Turner's (2009) Proceeding 'Identifying and developing the mathematical apprehensions of beginning primary school teachers' provides a useful illustration here, being assigned in the Survey to the keyword-groups of teachers, affect and cognition. After removal of stop-words, $43 \%$ of the content of this Proceeding is characteristic of the TM Topic teachers' subject knowledge. The coverage of affect and cognition within this Proceeding, while it is there, is more limited. With a similar pattern across Proceedings -62 Proceedings were categorised under both affect and teachers, for example - this illustrates how the Survey and TM robustly identify the strongest themes.

\section{Themes, trends and comparisons with previous reviews}

We now address our first and second research questions by discussing the key themes and trends over time arising from the combined analyses, comparing and contrasting these outcomes with those found in other international reviews and in Nickson's (2003) earlier BSRLM review.

\section{Mathematical content}

Mathematical content areas (e.g. algebra) were a strong feature of the survey, representing $12 \%$ of the applied keyword-groups. Likewise, seven of the TM topics cover mathematical content. Each of these topics - calculation, algebra, geometry, multiplicative reasoning, calculus, statistics and probability, and modelling - map onto 
the survey outcomes. The identified mathematical content areas and the strength of focus on these are in line with other recent European, US and international reviews (e.g. Adler, Alshwaikh, Essack, \& Gcsamba, 2016; Dreyfus et al., 2018; Inglis \& Foster, 2018; Xu, 2010). There is also similarity between these identified areas and those found in Nickson's (2003) earlier review.

Trends for each topic are shown in Figure 2. Of note, the only topic here where the focus has increased over the review period is multiplicative reasoning. In a change from earlier reviews, the co-occurrence of technology with either algebraic reasoning or geometry is high, with 20 Proceedings covering both algebraic reasoning and technology (representing 35\% of all Proceedings examining algebraic reasoning) and 18 Proceedings covering both geometry and technology (50\% of Proceedings examining geometry). This aligns with a recent Australasian review of research into the use of digital technologies in mathematics education (Geiger et al., 2016).

Number and calculation. Number and calculation was the most common content area across the Proceedings, but was heavily weighted towards the primary phase. While Proceedings examining the early years were limited overall, the development of number sense in young children was identified as one of just two main foci in the Proceedings that had an early-years focus. These Proceedings tended to appear in the later years of the review period, supporting Rezat and Ejersbo's (2018) findings on the work of the Arithmetic and Number Systems Thematic Working Group (TWG) at the Congress of the European Society for Research in Mathematics Education (CERME), where number sense as a concept appeared to be gaining greater interest among researchers (reflected in the inclusion of this topic in both the 2015 and 2017 CERME plenary addresses). The decline in interest in number and calculation $(r=-.604)$ across the Proceedings, which parallels Inglis and Foster's (2018) finding of less attention being given to the topic of 
addition and subtraction in JRME/ESM, may in part be accounted for by a peak in interest in 2003, possibly an artefact of the increased policy focus in England at this time, as findings started to emerge from early evaluations of the National Numeracy Strategy, introduced into primary schools in 1999 (Department for Education and Employment [DfEE], 1999).

Algebraic reasoning and geometry. Algebraic reasoning and geometry were dominant across the Proceedings, with both heavily weighted towards the secondary phase. This aligns with other reviews: both emerged as topics in Inglis and Foster's (2018) review, both featured as CERME TWGs, and both appeared variously as specific areas of interest in the reviews of recent research from South Africa (Adler et al., 2016), China (Xu, 2014) and Australasia (Makar et al., 2016). As with CERME's reviews (Hodgen, Oldenburg, \& Strømskag, 2018; Kuzniak, Richard, \& Michael-Chrysanthou, 2018), which highlighted a focus on research on how algebra and geometry should be taught, the Proceedings examining these areas also focused strongly on approaches to teaching.

Multiplicative reasoning. While Inglis and Foster (2018) found a focus on multiplicative reasoning within their topic of rational numbers (with characteristic words including division, multiplication and multiplicative), this topic is absent in other reviews and from other working groups. Multiplicative reasoning is, however, a relatively strong feature of the BSRLM Proceedings. It is also the only mathematical content area with a strong overall positive trajectory in interest over the review period $(r$ $=.729)$. This trend may result from the 11 Proceedings between 2008 and 2018 reporting or drawing on data from the Increasing Competence and Confidence in Algebra and Multiplicative Structures project (e.g. Hodgen, Küchemann, Brown, \& Coe, 2008), demonstrating the impact that an individual large project or group of 
researchers can have on trends locally when the total number of Proceedings is relatively small.

Statistics and probability, Calculus and Modelling. These three areas share some similarities. All three were generated within the TM and featured - fairly equally - in the coverage of mathematical topics in the survey. Statistics and probability and calculus featured as topics in Inglis and Foster's (2018) JRME/ESM review, while modelling featured within their topics of visualization and problem solving. All three have corresponding CERME TWGs. In line with CERME's review (Winsløw, Gueudet, Hochmuth \& Nardi, 2018), the majority of Proceedings covering calculus also addressed university mathematics; this may account for the decline noted over the review period (and mirroring Inglis \& Foster's, 2018, decline in formal analyses), given the overall decline in Proceedings focused on university mathematics.

\section{Mathematical thinking}

Closely linked with the mathematical content areas, mathematical thinking emerged as a central although less dominant area in the survey, representing 7\% of the keywordgroup coding and being present in 159 Proceedings. From the TM, three topics were identified: proof, abstraction and generalisation, and problem solving.

Problem solving displayed an increase in interest over the review period $(r=$ .511), appeared in Inglis and Foster's (2018) review, and was identified as a focus of reviews internationally (Jayarajah, Saat, Rauf \& Amnah, 2014; Makar et al., 2016). The survey suggested that the focus of problem solving changed with age-phase; in the primary phase, the emphasis was on reasoning about number and calculation; in the secondary phase this shifted to algebraic reasoning. Problem solving co-occurred with mathematical content, teachers and classroom/pedagogic approaches. Furthermore, 12\% 
of Proceedings covering problem solving co-occurred with affect; analysis of these Proceedings suggested that while many focused on pre-service teachers and their anxiety when faced with mathematical problems, persistence, perseverance and resilience emerged as co-occurring interests in Proceedings examining pupils' problem solving in the later years of the review period.

In contrast to problem solving, the number of Proceedings exploring proof, and abstraction and generalisation declined over the review period $(r=-.535$ and $r=-.462$ respectively). This contrasts with Inglis and Foster (2018) and Mariotti, DurandGuerrier and Stylianides (2018), who both found increased prominence for these areas, perhaps suggesting that work in these areas may be more likely to be published in journals than in conference proceedings. Proceedings examining aspects of proof, and abstraction and generalisation, tended not to co-occur with other keyword groups, the only exception being with mathematical topic areas, indicating that much of the work on proof, and abstraction and generalisation, was taking place in the context of algebraic reasoning, geometry and calculus.

\section{Teachers and teacher development}

Teachers was the most prominent keyword-group in the survey, covering a third of the Proceedings, and six of the topics generated in the TM examined teachers. This strong focus concurs with Adler et al.'s (2016) review, where 39\% of papers focused on teachers, and is most likely related to the predominance of teacher educators conducting mathematics education research in the UK. The focus on teachers increased steadily but consistently during the review period (for all six topics combined, $r=.453$ ), mirroring the topic of teachers' knowledge and beliefs, which includes pre-service teachers, in Inglis and Foster's (2018) review. Of the six teacher-focused topics in the TM, only teacher subject knowledge has declined in interest $(r=-.493)$. 
Within the teachers keyword-group, 35\% of Proceedings focused on aspects of pre-service or Initial Teacher Training (ITT). This reflects the review of work at CERME in the TWG Mathematics teacher education and professional development, where this was noted to be a stable, ongoing, strong theme around the world. This was also found in Xu's review (2014), where it was noted that the training of teachers and the curriculum and instruction for pre-service teachers was a 'hot topic' in China. While the increase in interest over the review period in the topic 'preservice teacher education' is strong $(r=.696)$, the survey revealed a peak in interest at the beginning of the review period in 2003. Examination of the Proceedings written at this time suggests that this peak may be partially accounted for by the government's introduction of compulsory mathematics skills tests for all ITT students in England in 2000. These tests raised questions about the nature of mathematics subject knowledge for teaching and whether a skills test was a valid way to assess this. A similar trend is emerging in Australia, where the Australian Institute for Teaching and School Leadership introduced national testing for trainee teachers in 2015; exploratory studies there are now beginning to engage with the effects of this (Anthony, Cooke \& Muir, 2016). While skills tests represent one aspect of teacher subject knowledge, we found in the survey that the cooccurrence of ITT and teacher subject knowledge was extensive, with $85 \%$ of Proceedings coded for teacher subject knowledge also coded for ITT.

While ITT accounted for the majority of Proceedings in the teachers keywordgroup, in-service professional learning / continuing professional development (CPD) also featured strongly, accounting for $25 \%$ of this keyword-group, with a small but steady growth in interest over the review period. The focus on CPD, and, within this, research-informed CPD, reflects a change from Nickson's (2003) review of BSRLM Proceedings from 1995-2002, where it was noted that little attention had been directed 
towards this area. Multiple factors may account for this: the focus on CPD within the National Strategies, universities diversifying their offering in light of a move towards school-centred ITT and the inception of the Mathematics Specialist Teacher Programme. Two TM topics - teacher collaborative research and teachers as researchers - reflect the area of teacher-research, with teachers taking ownership of their CPD and a growth in collaborative projects (either between teachers or between teachers and higher education institutions [HEIs]). Teacher inquiry also features strongly, perhaps boosting the appearance of interest in teachers as researchers. This is reflected in Xu's (2014) review, where the new expectation in China for teachers to be involved in action research has seen an increase in publications in this field. A similar pattern is emerging in Australia, where teacher inquiry and action research now feature heavily in professional learning programmes (Beswick, Anderson \& Hurst, 2016), while the CERME Review (Hošpesová, Carrillo \& Santos, 2018) noted that teacher inquiry represents a strongly developing trend.

Separating teachers and their practice is complex; hence, we see classroom practice emerging within the teachers keyword-group in the survey and being generated through the TM. Proceedings here cover specific issues in teaching and learning, and so are discussed below. In relation to classroom practice, the survey found only an infrequent focus on Teaching Assistants (TAs), who were the study population in only four Proceedings. This absence is also found in the Australasian review, where the role of TAs was considered under-researched (Faragher, Hill \& Clarke, 2016).

\section{Issues in teaching and learning mathematics}

Thirty-nine percent of Proceedings had keywords related to teaching and learning mathematics - unsurprisingly, given the focus of BSRLM. Likewise, nine of the $30 \mathrm{TM}$ topics examine these issues. Internationally, this reflects Inglis and Foster's (2018) 
review, where nine of their topics (out of 28) covered issues related to teaching and learning mathematics, and it mirrors Jayarajah et al.'s (2014) review of Malaysian articles, where $36 \%$ of papers examined these issues.

Pedagogic tools and tasks: Manipulatives and representations were coded in the survey as pedagogic tools and also appeared as a topic within the TM. They represent the strongest increase over the review period in topics considering issues in teaching and learning mathematics $(r=.727)$, with this growth in interest reflected in the inception of a new CERME TWG on Representations in Mathematics Teaching and Learning in 2017. The majority of Proceedings focus on the primary phase, where, since 2015, they have examined mastery approaches (including concrete-pictorial-abstract; e.g. Duckworth, Lawley, Siddiqui \& Stevenson, 2015) and the bar model (e.g. Spencer \& Fielding, 2015); both are likely to reflect the introduction of the new National Curriculum in 2014 (Department for Education [DfE], 2013) and recent interest in Shanghai and Singapore (see Boylan, Maxwell, Wolstenholme, Jay \& Demack, 2018). In the secondary phase, the emphasis shifted towards the use of technology. This interest is shown in discussion of technologies across multiple reviews, with three related TWGs at CERME. Although the trend over the review period is flat overall, this hides a sustained increase in interest between 2005 and 2011 (perhaps reflecting the proliferation of technology, particularly interactive white boards, going into schools during this period) followed by a recent decline. In relation to teaching materials, example construction appeared as a topic, but one experiencing a decline in interest over the review period. This decline was surprising; given the recent interest in mastery, we expected to see a renewed interest in tasks, textbooks and, specifically in relation to mastery, issues such as variation theory (see Marton, 2015). It may be that any renewed interest in the area is yet to materialise; a CERME TWG Curricular Resources and Task 
Design in Mathematics Education was established in 2017, suggesting potential development in the area.

Classroom talk and interaction: Classroom talk and interaction was a keyword-group in the survey, covering both classroom interaction and discourse. Similar topics were generated in the TM (classroom interactions and semiotics and discourse). Classroom interactions displays a slight increase in interest over the review period $(r=.401)-$ with a substantial increase in interest in the sub-areas of noticing and attending - yet semiotics and discourse experienced a decrease in interest of similar magnitude ( $r=-$ .478). These trends are intriguing when contrasted with other reviews; no other review examined here explored issues of classroom interaction, but classroom discourse does repeatedly appear as a focus elsewhere (e.g. R. Hunter, Hunter, Jorgensen \& Heng Choy, 2016; Inglis \& Foster, 2018; Planas, Morgan \& Schütte, 2018).

Participation in mathematics: Participation in mathematics was generated as a topic in the TM and, although not a keyword-group in the survey, was discussed within issues of affect and social context. These issues, which transcend participation, are regular and consistent features of other reviews, with themes such as equity, gender, diversity and motivation. Although interest levels have remained steady, this was the keyword-group covered least in the survey. We note that there appears to be no direct coverage of this area in any other review.

Curriculum, policy and assessment: A strong match between TM topics and the survey outcomes emerged in relation to issues of the intended and operationalised curriculum and its assessment. While overall trends have been stable over the review period in curriculum/policy (with an early decrease) and in assessment (with an early increase), 
these areas represent a substantial proportion of the corpus. Internationally, the picture is the same: curriculum, including curriculum reform, is a topic in Inglis and Foster's (2018) review, a TWG on Assessment in Mathematics Education was established at CERME in 2017, and curriculum and assessment represent a substantial discussion in the Australasian review (Serow, Callingham \& Tout, 2016; Way, Bobis, Lamb \& Higgins, 2016). Proceedings coded here intersect almost all other areas of discussion, with substantial policy imperatives in the UK occurring during the period of the review. The survey suggests that specific curricular reforms may have some bearing on trends within the Proceedings; while policy appears to be relatively stable in terms of level of interest over the review period, this result is distorted by the emergence since 2014 of Proceedings considering mastery, with 16 Proceedings exploring this issue in various ways and interest growing steadily between 2014 and $2018(r=.740)$.

\section{Post-16 and university mathematics}

Internationally, reviews of Malaysian (Jayarajah et al., 2014) and Australasian (Makar et al., 2016) research see university mathematics as a developing field. Analysis of cooccurring keyword-groups with both phases reveals some differences. While $15 \%$ of Proceedings coded as post-16 also examined curriculum and pedagogy, this was only $6 \%$ for university mathematics. On the other hand, fewer than $6 \%$ of post- 16 Proceedings examined teachers/lecturers, but this rose to almost $20 \%$ for university mathematics. In line with reviews of work in the university phase at CERME (Winsløw et al., 2018), both phases co-occurred strongly with the affect keyword-group, with Proceedings often looking at beliefs and interventions around participation. In relation to this, and reflecting Coupland, Dunn, Galligan, Oates and Trenholm's (2016) Australasia review findings, we found a co-occurrence of post-16 and university mathematics with transition. While discussion of transition between all education stages 
was limited to six Proceedings, all six were located in the transition to post-16 or university mathematics.

\section{Research approaches}

Altogether, 71\% (576) of Proceedings between 2003 and 2018 reported empirical studies, with the number being stable across the review period $(r=.165)$. Past and present reviews show that this is broadly in line with the international picture: Hanna and Sidoli's (2002) review of ESM articles published between 1990 and 1998 categorised $77 \%$ as empirical, while Adler et al. (2016) found $85 \%$ of published South African research to be empirical. Table 2 shows the use of qualitative, quantitative and mixed-methods approaches across the Proceedings, contrasting these with reviews past and present. BSRLM approaches sit in line with other reviews, although the slight but steady increase in the use of quantitative approaches $(r=.315)$ over the review period is noteworthy. Of these quantitative studies, 17 took an experimental approach.

\section{INSERT TABLE 2 NEAR HERE}

\section{INSERT TABLE 3 NEAR HERE}

Table 3 shows the use of qualitative, quantitative and mixed-methods approaches by theme. The distribution of research approaches shows a fairly consistent pattern across each theme, with some notable exceptions: classroom-based themes (talk and interaction, and approaches) are more likely to employ qualitative approaches, while themes with a higher use of quantitative (and mixed-methods) approaches include developmental trajectories and Special Educational Needs and Disability (SEND), and assessment and accountability.

\section{Conclusion}

We used two different methods to analyse the entire dataset of the Proceedings of the 
British Society for Research into Learning Mathematics from 2003 to 2018 (813

Proceedings) and compared the results. We now summarise the main findings regarding the topics obtained and then discuss the methodological implications arising from this comparative synthesis.

\section{Main findings}

Our synthesis identified the strongest topics as mathematical content (12\% of the applied keyword-groups and seven of the TM topics) and teachers (16\% of the applied keyword-groups and six of the TM topics). Within mathematical content, number and calculation was the dominant area, but multiplicative reasoning was noteworthy for having increased in prevalence during the review period. Within the teachers topic, initial teacher education predominated, which we ascribe to the many researchers in mathematics education with roles as teacher educators to pre-service teachers and the natural opportunity to research their student teachers. Again, similar patterns or trends were found within comparison research syntheses.

These two areas in particular are strongly represented within the Proceedings, and mathematics education research more broadly, and clearly represent critical domains in which important work is being and needs to be done. We do, however, wish to highlight areas that seem to us to be underrepresented within the corpus we have analysed. While primary, secondary (including post-16) and higher education all receive a lot of attention, other phases, notably further education, early years and adult education are almost absent. Each of these neglected groups represent sizeable proportions of learners (approximately 35\% of 3-19 education and all of non-HE adult education) and important aspects of the overall picture in understanding learning and teaching in mathematics education and these would seem to be very important and fruitful areas for future research. 
As mentioned above, our findings were generally closely in line with those from an earlier review of the Proceedings (1995-2002), as well as with those from other reviews. Overall, we found considerable similarity between the issues discussed as well as similar trends over time. This leads us to conclude that contributions to the BSRLM Proceedings are broadly representative of mathematics education discourse internationally.

\section{Methodological Implications}

Our two methods were (i) a quantitative corpus-survey combined with qualitative thematic coding, and (ii) topic modelling (TM), a technique from computational linguistics (Blei, $\mathrm{Ng}$, \& Jordan, 2003). We found strong convergence between the findings from the two strikingly different methods. A review using either one of these methods alone would not have reached substantially different conclusions. This raises questions about how best to make use of the economies of time and effort residing in the TM approach when conducting future reviews.

Although TMs are generated computationally, as we have described in this paper, interpretation of the output does entail reading and interpreting papers from within each topic, so we see TM as a mixed methods approach and not a purely quantitative one. Purely quantitative approaches to synthesis are available, such as simply reporting the number of papers falling under each keyword, and purely qualitative analyses are also a clear possibility, although this would require a sampling approach for a large corpus, and might also be vulnerable to researcher bias.

We do not see either approach as generally superior; on the contrary, we suggest that, where the corpus is large enough, topic modelling provides a powerful technique for saving time and structuring the subsequent interpretive activity of a review in an objective way. The findings from an initial TM may be useful to direct further 
qualitative work, which might then raise additional questions which could prompt more topic modelling. For example, in our case, the survey revealed a peak in interest in the topic 'preservice teacher education' at the beginning of the review period in 2003. Subsequent qualitative analysis of the Proceedings written around this time suggested that this might be partially explained by the government's introduction of compulsory mathematics skills tests for all ITT students in England in 2000. In this way, findings from the TM raised questions that were explored through qualitative analysis and the two methods operate to the benefit of each.

We conclude that the efficiency of the topic modelling method makes it a powerful option to include within a mixed methods methodology to research synthesis.

Acknowledgement: The authors would like to thank BSRLM for their support and funding to produce the survey and thematic review underpinning this paper. We would also like to thank the editor and the anonymous reviewers for their very helpful comments on a previous version of this paper.

\section{Note}

The keyword-groups arising from the survey, the keywords and the 30 TM topics, their characteristic words and the composition of the Proceedings by topic are all available in our dataset at https://doi.org/10.6084/m9.figshare.8282744

\section{Disclosure statement}

No potential conflict of interest was reported by the authors.

\section{References:}

Adler, J., Alshwaikh, J., Essack, R. \& Gcsamba, L. (2016). Mathematics education research in South Africa 2007-2015: Review and reflection. African Journal of 
Research in Mathematics, Science and Technology Education, 21(1), 1-14. https://doi.org/10.1080/18117295.2016.1265858

Anthony, G., Cooke, A. \& Muir, T. (2016). Challenges, reforms, and learning in initial teacher education. In K. Makar, S. Dole, J. Visnovska, M. Goos, A. Bennison \& K. Fry (Eds.), Research in mathematics education in Australasia 2012-2015 (pp. 305-327). Singapore: Springer. https://doi.org/10.1007/978-981-10-1419-2_15

Beswick, K., Anderson, J. \& Hurst, C. (2016). The education and development of practicing teachers. In K. Makar, S. Dole, J. Visnovska, M. Goos, A. Bennison \& K. Fry (Eds.), Research in mathematics education in Australasia 2012-2015 (pp. 329-352). Singapore: Springer. https://doi.org/10.1007/978-981-10-1419$\underline{2 \_16}$

Blei, D., Ng, A. \& Jordan, M. (2003). Latent Dirichlet allocation, The Journal of Machine Learning Research, 3, 993-1022.

Borthwick, A. \& Harcourt-Heath, M. (2007, March). Calculation strategies used by year 5 children. In D. Küchemann (Ed.), Proceedings of the British Society for Research into Learning Mathematics (pp. 12-17). London: BSRLM.

Boylan, M., Maxwell, B., Wolstenholme, C., Jay, T. \& Demack, S. (2018). The mathematics teacher exchange and 'mastery' in England: The evidence for the efficacy of component practices, Education Sciences, 8(4), 202-232. https://doi.org/10.3390/educsci8040202

Coupland, M., Dunn, P., Galligan, L., Oates, G. \& Trenholm, S. (2016). Tertiary mathematics education. In K. Makar, S. Dole, J. Visnovska, M. Goos, A. Bennison \& K. Fry (Eds.), Research in mathematics education in Australasia 2012-2015 (pp. 187-211). Singapore: Springer. https://doi.org/10.1007/978-981$\underline{10-1419-2 \_10}$

Department for Education (2013). National curriculum in England: Mathematics programmes of study. London: Department for Education.

Department for Education and Employment (1999). The National Numeracy Strategy: Framework for teaching mathematics from reception to year 6. London: DfEE.

Dreyfus, T., Artigue, M., Potari, D., Prediger, S. \& Ruthven, K. (Eds.). (2018) Developing research in mathematics education: Twenty years of communication, cooperation and collaboration in Europe. London: Routledge. 
Duckworth, L., Lawley, S., Siddiqui, M. \& Stevenson, M. (2015, November). Maths Hub, mastery and messy research. In G. Adams (Ed.). Proceedings of the British Society for Research into Learning Mathematics (pp. 31-36). London: BSRLM.

Eickhoff, M. \& Neuss, N. (2017, June). Topic modelling methodology: Its use in information systems and other managerial disciplines. In I. Ramos, V. Tuunainen \& H. Krcmar (Eds.), Proceedings of the 25th European Conference on Information Systems (pp. 1327-1347). Guimarães, Portugal: ECIS.

Faragher, R., Hill, J. \& Clarke, B. (2016). Inclusive practices in mathematics education. In K. Makar, S. Dole, J. Visnovska, M. Goos, A. Bennison \& K. Fry (Eds.), Research in mathematics education in Australasia 2012-2015 (pp. 119-141). Singapore: Springer. https://doi.org/10.1007/978-981-10-1419-2_7

Geiger, V., Calder, N., Tan, H., Loong, E., Miller, J. \& Larkin, K. (2016). Transformations of teaching and learning through digital technologies. In K. Makar, S. Dole, J. Visnovska, M. Goos, A. Bennison \& K. Fry (Eds.), Research in mathematics education in Australasia 2012-2015 (pp. 255-280). Singapore: Springer. https://doi.org/10.1007/978-981-10-1419-2_13

Hanna, G. \& Sidoli, N. (2002). The story of ESM, Educational Studies in Mathematics, 50(2), 123-156. https://doi.org/10.1023/A:1021162617070

Hodgen, J., Küchemann, D., Brown, M. \& Coe, R. (2008, November). Children's understandings of algebra 30 years on. In M. Joubert (Ed.). Proceedings of the British Society for Research into Learning Mathematics (pp. 36-41). London: BSRLM.

Hodgen, J., Oldenburg, R. \& Strømskag, H. (2018). Algebraic thinking. In T. Dreyfus, M. Artigue, D. Potari, S. Prediger, \& K. Ruthven (Eds.), Developing research in mathematics education: Twenty years of communication, cooperation and collaboration in Europe (pp. 32-45). London: Routledge.

Hošpesová, A., Carrillo, J. \& Santos, L. (2018). Mathematics teacher education and professional development. In T. Dreyfus, M. Artigue, D. Potari, S. Prediger, \& K. Ruthven (Eds.), Developing research in mathematics education: Twenty years of communication, cooperation and collaboration in Europe (pp. 181195). London: Routledge.

Hunter, R., Hunter, J., Jorgensen, R. \& Heng Choy, B. (2016). Innovative and powerful pedagogical practices in mathematics education. In K. Makar, S. Dole, J. Visnovska, M. Goos, A. Bennison \& K. Fry (Eds.), Research in mathematics 
education in Australasia 2012-2015 (pp. 213-234). Singapore: Springer. https://doi.org/10.1007/978-981-10-1419-2_11

Inglis, M. \& Foster, C. (2018). Five decades of mathematics education research, Journal for Research in Mathematics Education, 49(4), 462-500. https://doi.org/10.5951/jresematheduc.49.4.0462

Jayarajah, K., Saat, R., Rauf, A. \& Amnah, R. (2014). A review of science, technology, engineering \& mathematics (STEM) education research from 1999-2013: A Malaysian perspective, Eurasia Journal of Mathematics, Science \& Technology Education, 10(3), 155-163. https://doi.org/10.12973/eurasia.2014.1072a

Jones, K., Black, L. \& Coles, A. (2019). Marking 21 years of Research in Mathematics Education, Research in Mathematics Education, 21(1), 1-5. https://doi.org/10.1080/14794802.2019.1592336

Kuzniak, A., Richard, P. \& Michael-Chrysanthou, P. (2018). From geometrical thinking to geometrical working competencies. In T. Dreyfus, M. Artigue, D. Potari, S. Prediger, \& K. Ruthven (Eds.), Developing research in mathematics education: Twenty years of communication, cooperation and collaboration in Europe (pp. 8-22). London: Routledge.

Makar, K., Dole, S., Visnovska, J., Goos, M., Bennison, A. \& Fry, K. (Eds.). (2016). Research in mathematics education in Australasia 2012-2015. Singapore: Springer. https://doi.org/10.1007/978-981-10-1419-2_1

Mariotti, M., Durand-Guerrier, V. \& Stylianides, G. (2018). Argumentation and proof. In T. Dreyfus, M. Artigue, D. Potari, S. Prediger, \& K. Ruthven (Eds.), Developing research in mathematics education: Twenty years of communication, cooperation and collaboration in Europe (pp. 75-89). London: Routledge.

Marks, R., Barclay, N., Barnes, A. \& Treacy, P. (2019). Research review of BSRLM 2003-2017. Retrieved from BSRLM website: http://www.bsrlm.org.uk/wpcontent/uploads/2019/03/Research-Review-of-BSRLM-20032017_FEBRUARY2019.pdf

Marton, F. (2015). Necessary conditions of learning. London: Routledge.

McCallum, A. (2002). MALLET: MAchine Learning for LanguagE Toolkit. Retrieved from MALLET website: http://mallet.cs.umass.edu 
Nickson, M. (2003). A review of BSRLM research 1995-2002. Retrieved from BSRLM website: http://www.bsrlm.org.uk/wp-content/uploads/2016/09/BSRLMNickson-Review-of-BSRLM-Research-1995-2002.pdf

Nivens, R. \& Otten, S. (2017). Assessing journal quality in mathematics education, Journal for Research in Mathematics Education, 48(4), 348-368. https://doi.org/10.5951/jresematheduc.48.4.0348

Planas, N., Morgan, C. \& Schütte, M. (2018). Mathematics education and language: Lessons and directions from two decades of research. In T. Dreyfus, M. Artigue, D. Potari, S. Prediger, \& K. Ruthven (Eds.), Developing research in mathematics education: Twenty years of communication, cooperation and collaboration in Europe (pp. 196-210). London: Routledge.

Rezat, S. \& Ejersbo, L. (2018). Number sense in teaching and learning arithmetic. In T. Dreyfus, M. Artigue, D. Potari, S. Prediger, \& K. Ruthven (Eds.), Developing research in mathematics education: Twenty years of communication, cooperation and collaboration in Europe (pp. 23-31). London: Routledge.

Schoenfeld, A. (2016). Research in mathematics education, Review of Research in Education, 40(1), 497-528. https://doi.org/10.3102/0091732X16658650

Serow, P., Callingham, R. \& Tout, D. (2016). Assessment of mathematics learning: What are we doing? In K. Makar, S. Dole, J. Visnovska, M. Goos, A. Bennison \& K. Fry (Eds.), Research in mathematics education in Australasia 2012-2015 (pp. 235-54). Singapore: Springer. https://doi.org/10.1007/978-981-10-1419$\underline{2 \_12}$

Spencer, R. \& Fielding, H. (2015, November). Using the Singapore Bar Model to support the interpretation and understanding of word problems in Key Stage 2. In G. Adams (Ed.), Proceedings of the British Society for Research into Learning Mathematics (pp. 114-119). London: BSRLM.

Turner, F. (2009, November). Identifying and developing the mathematical apprehensions of beginning primary school teachers. In M. Joubert (Ed.), Proceedings of the British Society for Research into Learning Mathematics (pp. 91-96). London: BSRLM.

Way, J., Bobis, J., Lamb, J. \& Higgins, J. (2016). Researching curriculum, policy and leadership in mathematics education. In K. Makar, S. Dole, J. Visnovska, M. Goos, A. Bennison \& K. Fry (Eds.), Research in mathematics education in 
Australasia 2012-2015 (pp. 49-71). Singapore: Springer.

https://doi.org/10.1007/978-981-10-1419-2_4

Winsløw, C., Gueudet, G., Hochmuth, R. \& Nardi, E. (2018). Research on university mathematics education. In T. Dreyfus, M. Artigue, D. Potari, S. Prediger, \& K. Ruthven (Eds.), Developing research in mathematics education: Twenty years of communication, cooperation and collaboration in Europe (pp. 60-74). London: Routledge.

Xu, B. (2010). Research on mathematics education in China in the last decade: A review of journal articles, Frontiers of Education in China, 5(1), 130-155. https://doi.org/10.1007/s11516-010-0009-y

Yore, L. \& Lerman, S. (2008). Metasyntheses of qualitative research studies in mathematics and science education, International Journal of Science and Mathematics Education, 6(2), 217-223. https://doi.org/10.1007/s10763-0089128-9 
Table 1. Survey and TM outcomes. 


\begin{tabular}{|c|c|c|c|c|c|}
\hline $\begin{array}{l}\text { Survey } \\
\text { keyword- } \\
\text { group }\end{array}$ & $\begin{array}{l}\% \text { of all } \\
\text { applied } \\
\text { keyword- } \\
\text { groups }\end{array}$ & $\begin{array}{l}\text { Top keywords } \\
\text { in keyword- } \\
\text { groups } \\
\text { (coverage as \% } \\
\text { of keyword- } \\
\text { group) }\end{array}$ & TM Topics & Top 20 characteristic words of Topic & $\begin{array}{l}\text { Pearson's } \\
r\end{array}$ \\
\hline \multirow[t]{4}{*}{ Teachers } & \multirow[t]{4}{*}{16.4} & \multirow{4}{*}{$\begin{array}{l}\text { ITT (25); } \\
\text { Teacher subject } \\
\text { knowledge } \\
\text { (20); } \\
\text { Professional } \\
\text { learning (19); } \\
\text { Classroom } \\
\text { practice (16); } \\
\text { PCK (8); CPD } \\
(7)\end{array}$} & $\begin{array}{l}\text { Preservice } \\
\text { teacher } \\
\text { education }\end{array}$ & $\begin{array}{l}\text { teachers teaching mathematics teacher education school study data } \\
\text { prospective practice pre-service participants teach content } \\
\text { knowledge learning methods university secondary practices }\end{array}$ & .696 \\
\hline & & & $\begin{array}{l}\text { Teachers' } \\
\text { subject } \\
\text { knowledge }\end{array}$ & $\begin{array}{l}\text { knowledge teaching mathematics subject trainees primary content } \\
\text { teachers teacher trainee understanding Rowland mathematical } \\
\text { confidence PGCE quartet teach audit Shulman pedagogical }\end{array}$ & -.493 \\
\hline & & & $\begin{array}{l}\text { Teacher } \\
\text { collaborative } \\
\text { research }\end{array}$ & $\begin{array}{l}\text { mathematics learning research teaching education mathematical } \\
\text { understanding thinking classroom practice ideas development } \\
\text { educational approach learners study group university focus } \\
\text { knowledge }\end{array}$ & .060 \\
\hline & & & $\begin{array}{l}\text { Teachers' } \\
\text { classroom } \\
\text { practice }\end{array}$ & $\begin{array}{l}\text { lesson lessons teacher teachers teaching task classroom class work } \\
\text { teacher's observed analysis tasks observation study reform } \\
\text { resources content practice activity }\end{array}$ & .397 \\
\hline
\end{tabular}




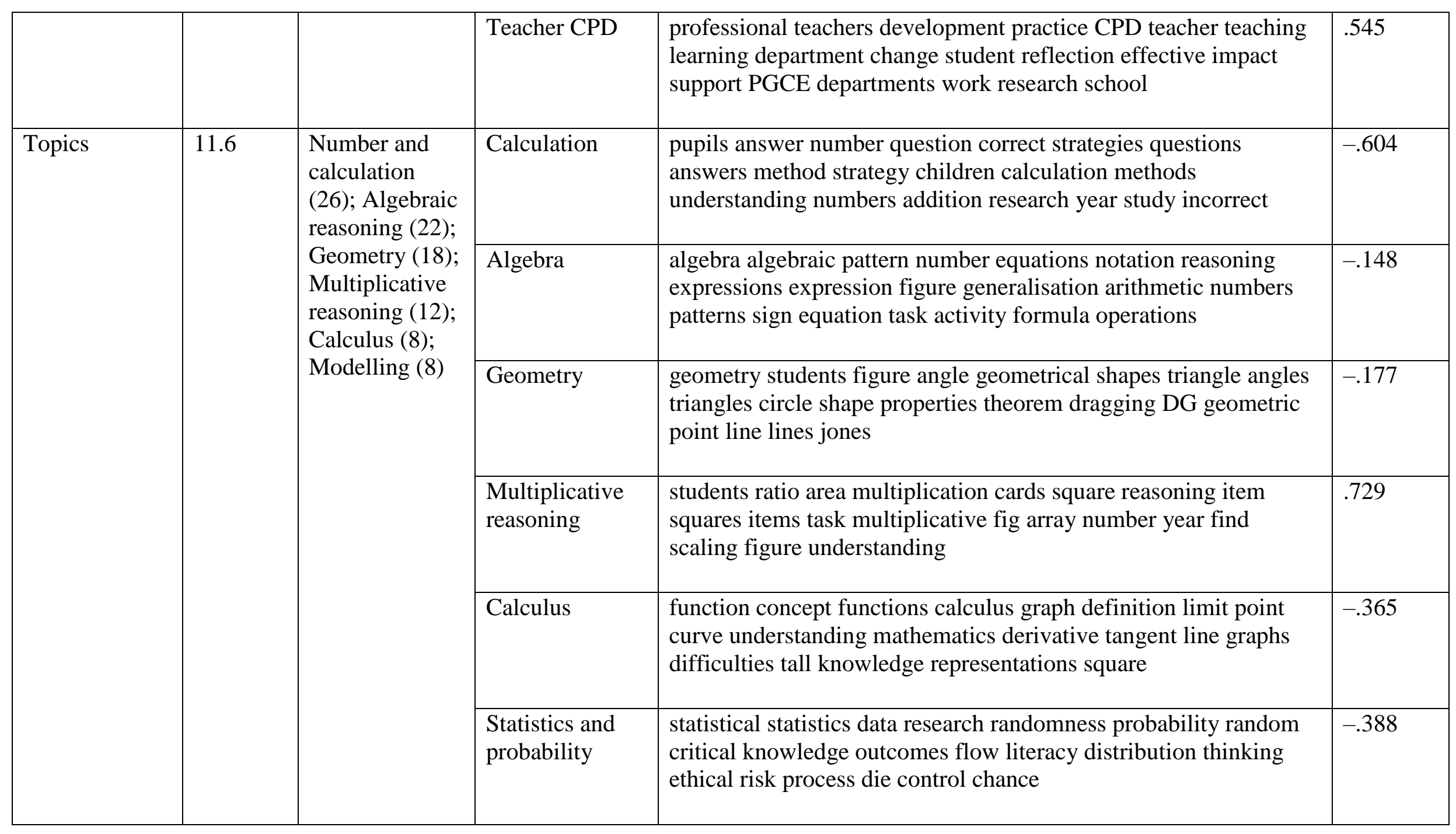




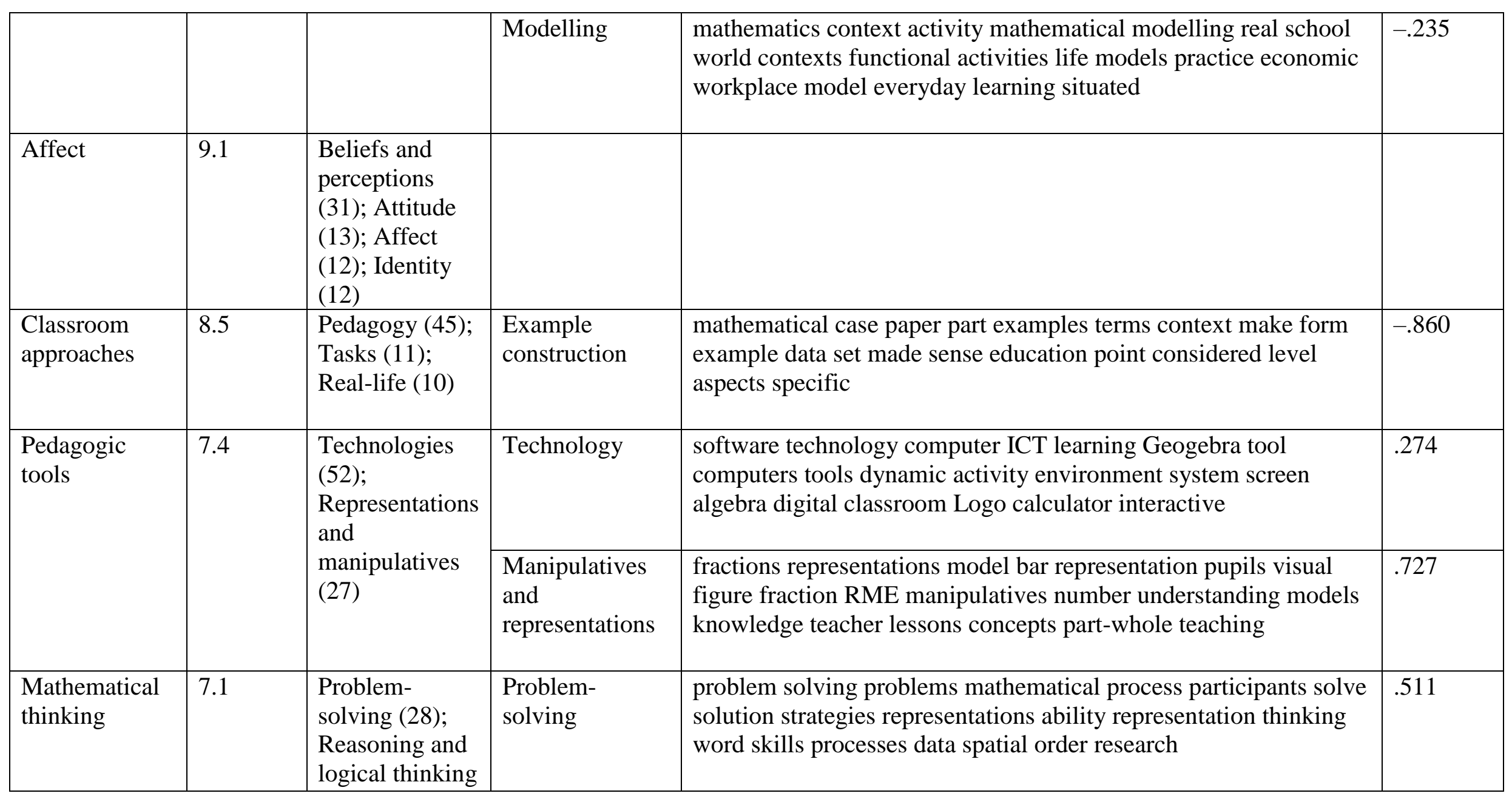




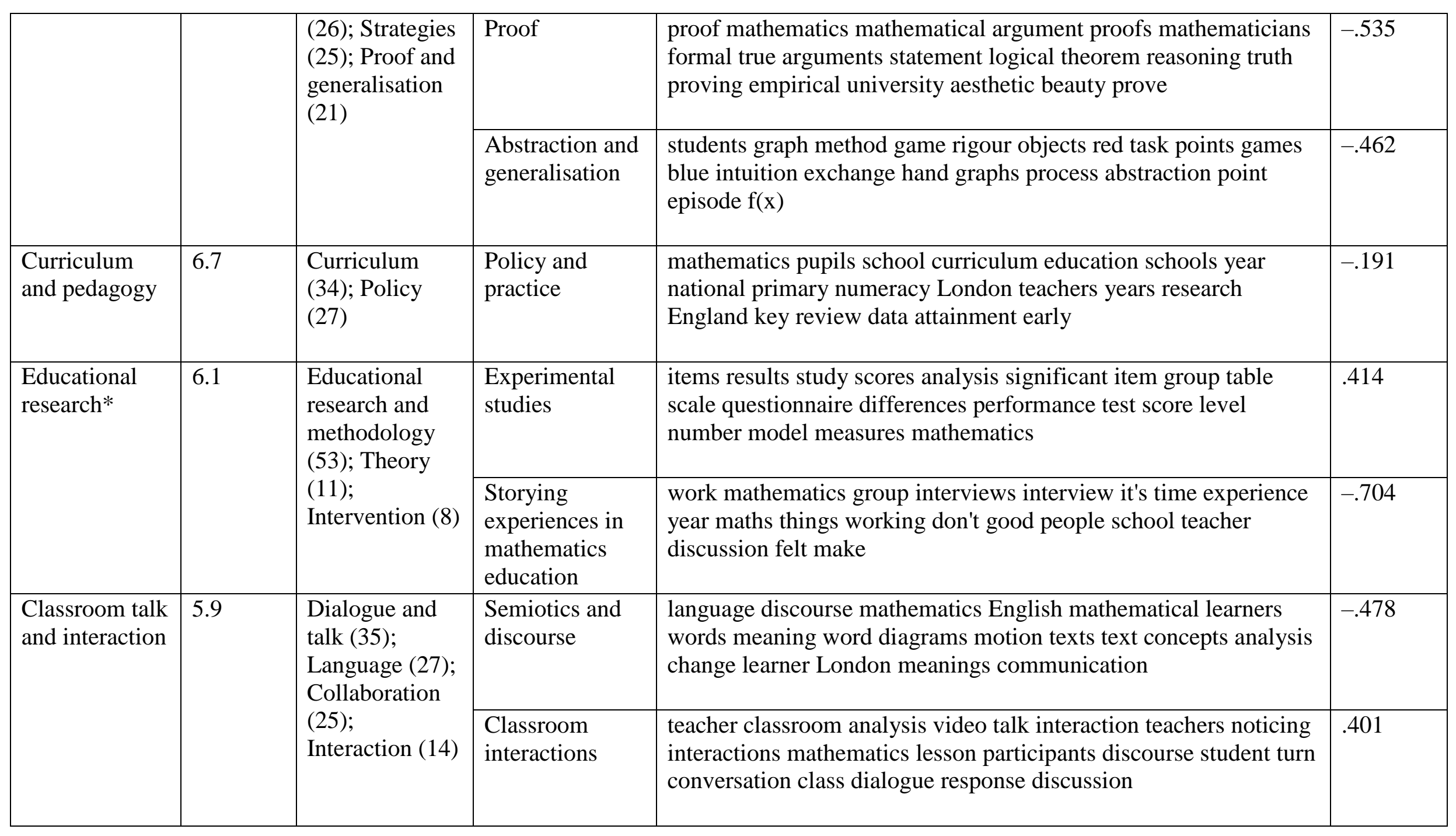




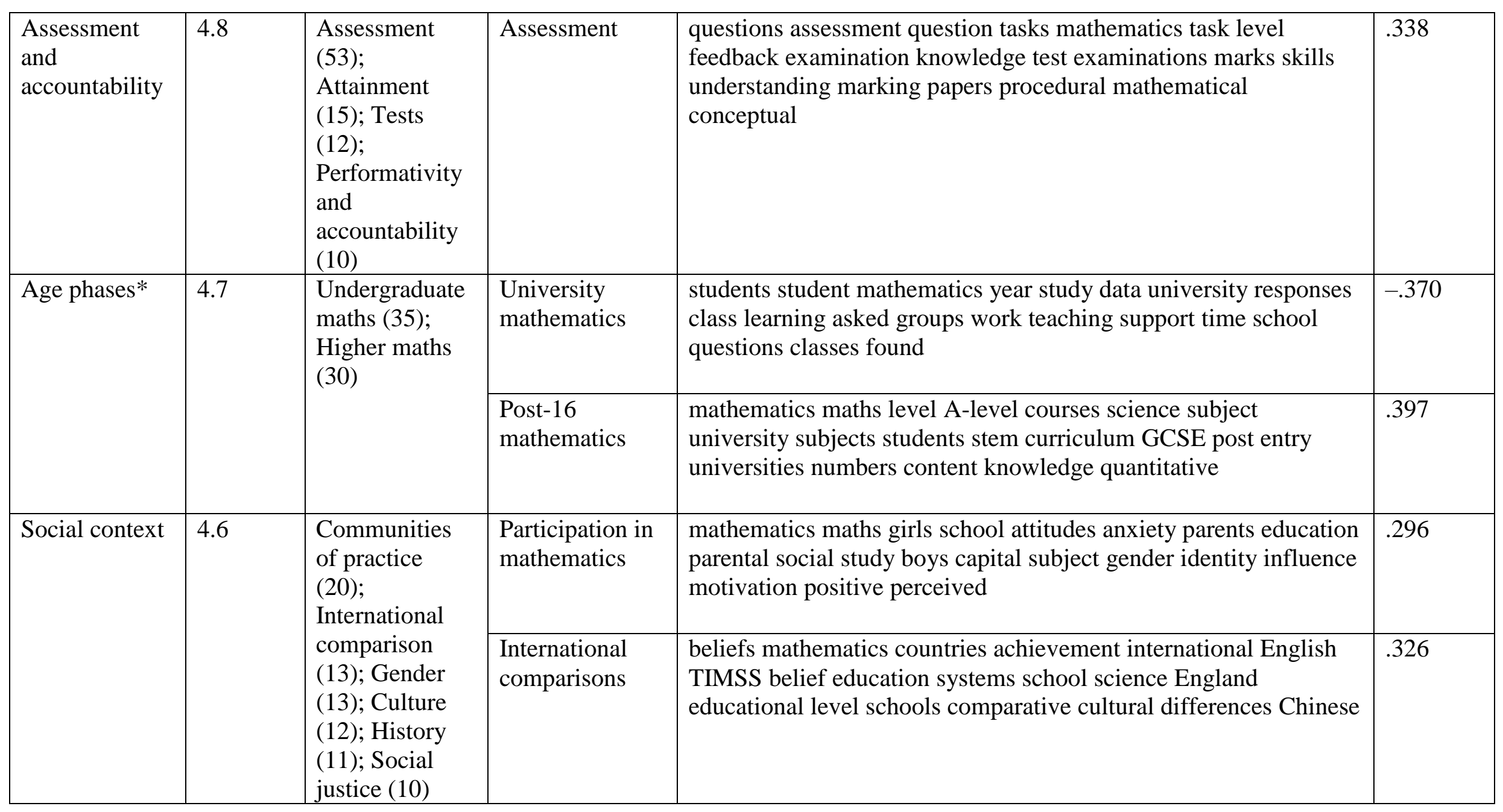




\begin{tabular}{|c|c|c|c|c|c|}
\hline Cognition & 4.5 & $\begin{array}{l}\text { Conceptual } \\
\text { understanding } \\
(50) \text {; Cognition } \\
\text { and } \\
\text { metacognition } \\
(27) \text {; } \\
\text { Connections } \\
\text { (10); Noticing / } \\
\text { attending (10) }\end{array}$ & & & \\
\hline
\end{tabular}

*Age-phases and Educational research are as classified in the keywords; i.e. if representing a key feature of the Proceeding. These categories do not represent the spread of age-phases or research approaches, which were captured separately. 
Table 2. Percentage of empirical Proceedings using different approaches across reviews

\begin{tabular}{|l|c|c|c|}
\hline & Qualitative & Quantitative & Mixed-methods \\
\hline $\begin{array}{l}\text { BSRLM Proceedings 2003-2018 } \\
\text { (Pearson's } r \text { showing trend over } \\
\text { period) }\end{array}$ & $67(-.048)$ & $14(.315)$ & $20(-.315)$ \\
\hline $\begin{array}{l}\text { Hanna \& Sidoli's (2002) review of } \\
\text { ESM articles (1990-1998) }\end{array}$ & 85 & 15 & Not recorded \\
\hline $\begin{array}{l}\text { Adler et al.'s (2016) review of } \\
\text { research in South Africa 2007-2015 }\end{array}$ & 58 & 20 & 22 \\
\hline $\begin{array}{l}\text { Jayarajah et al.'s (2014) review of } \\
\text { Malaysian publications 1999-2013 }\end{array}$ & 56 & 18 & 27 \\
\hline
\end{tabular}

* We recognise that qualitative, quantitative and mixed-methods approaches are not always defined identically. Here, we rely on the categorisation of the reviews' authors, as not enough information is provided to ascertain consistency of meaning. 
Table 3. Methodological approach of empirical Proceedings examining each keywordgroup $(\%)$

\begin{tabular}{|l|c|c|c|}
\hline & Qualitative & Quantitative & Mixed-methods \\
\hline Affect & 60 & 13 & 26 \\
\hline Assessment and accountability & 42 & 32 & 26 \\
\hline Classroom approaches & 78 & 10 & 13 \\
\hline Classroom talk and interaction & 91 & 1 & 8 \\
\hline Cognition & 62 & 18 & 20 \\
\hline Curriculum and pedagogy & 67 & 15 & 18 \\
\hline Developmental trajectories and SEND & 44 & 27 & 29 \\
\hline Educational research & 65 & 15 & 20 \\
\hline Mathematical thinking & 67 & 12 & 21 \\
\hline Pedagogic tools & 79 & 7 & 14 \\
\hline Social context & 63 & 18 & 19 \\
\hline Teachers & 70 & 8 & 22 \\
\hline Topics & 65 & 17 & 18 \\
\hline
\end{tabular}


Figure 1. Perplexity graph used to inform decision about the number of topics

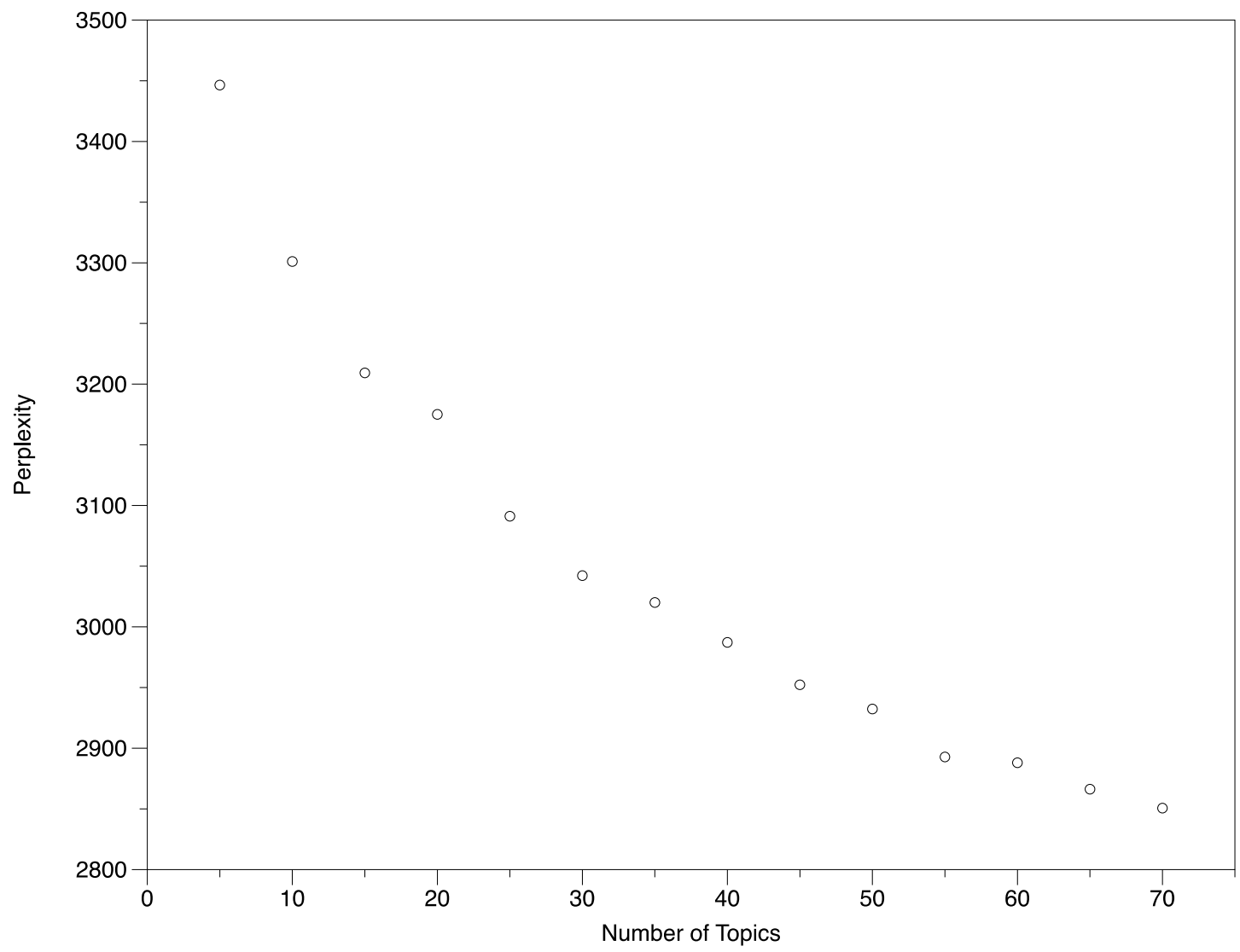


Figure 2. Trend graphs for each TM Topic 


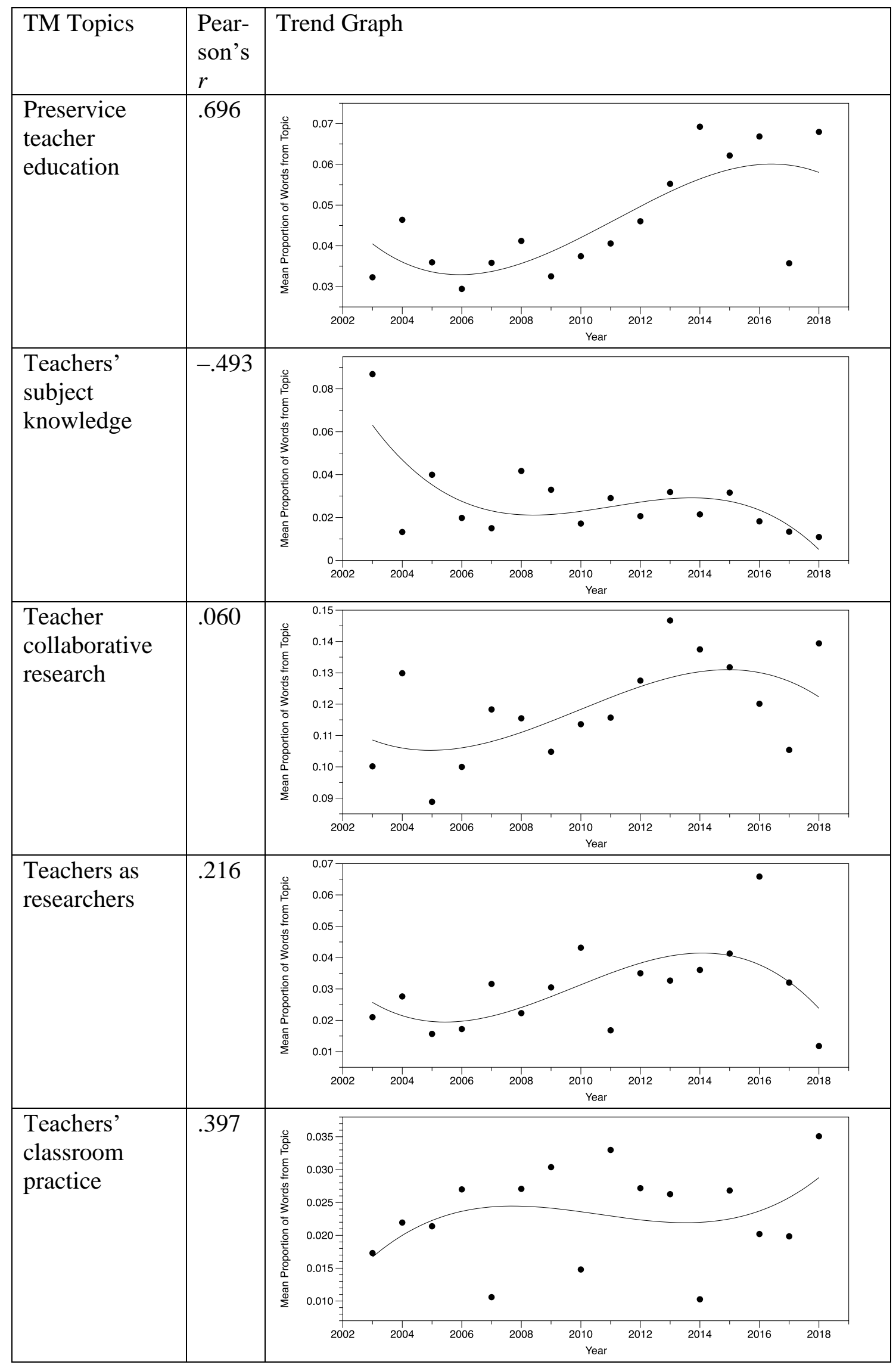




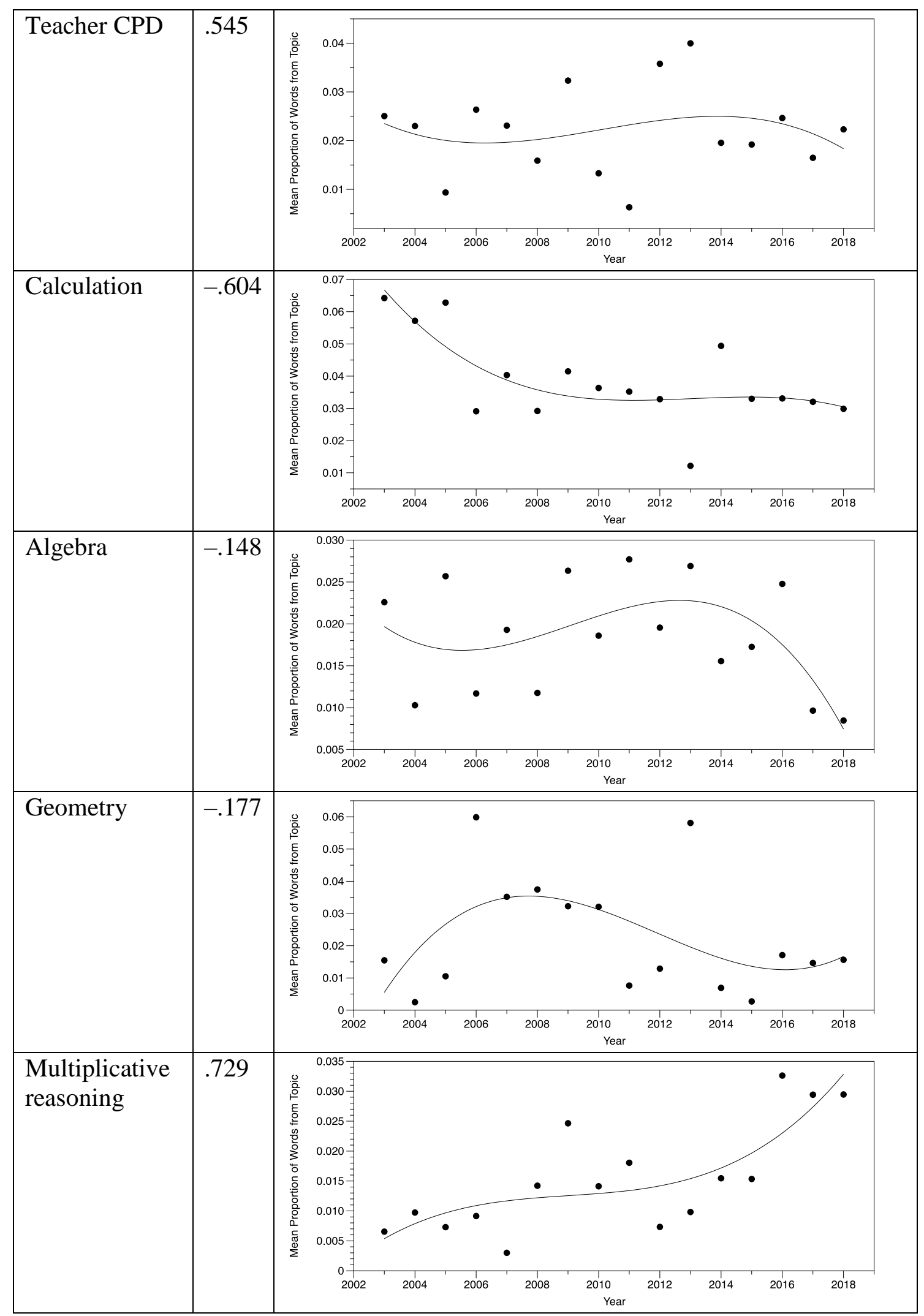




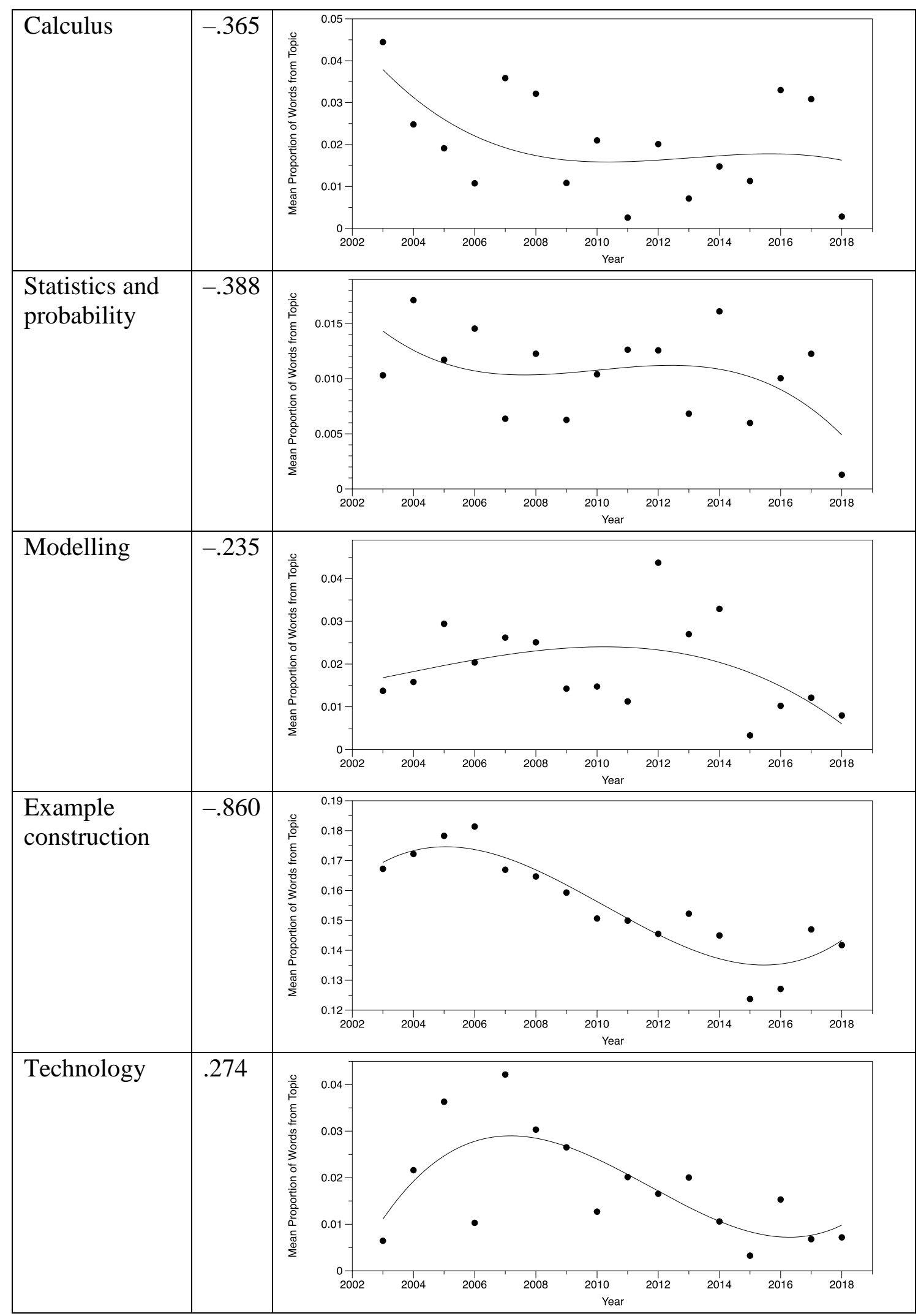




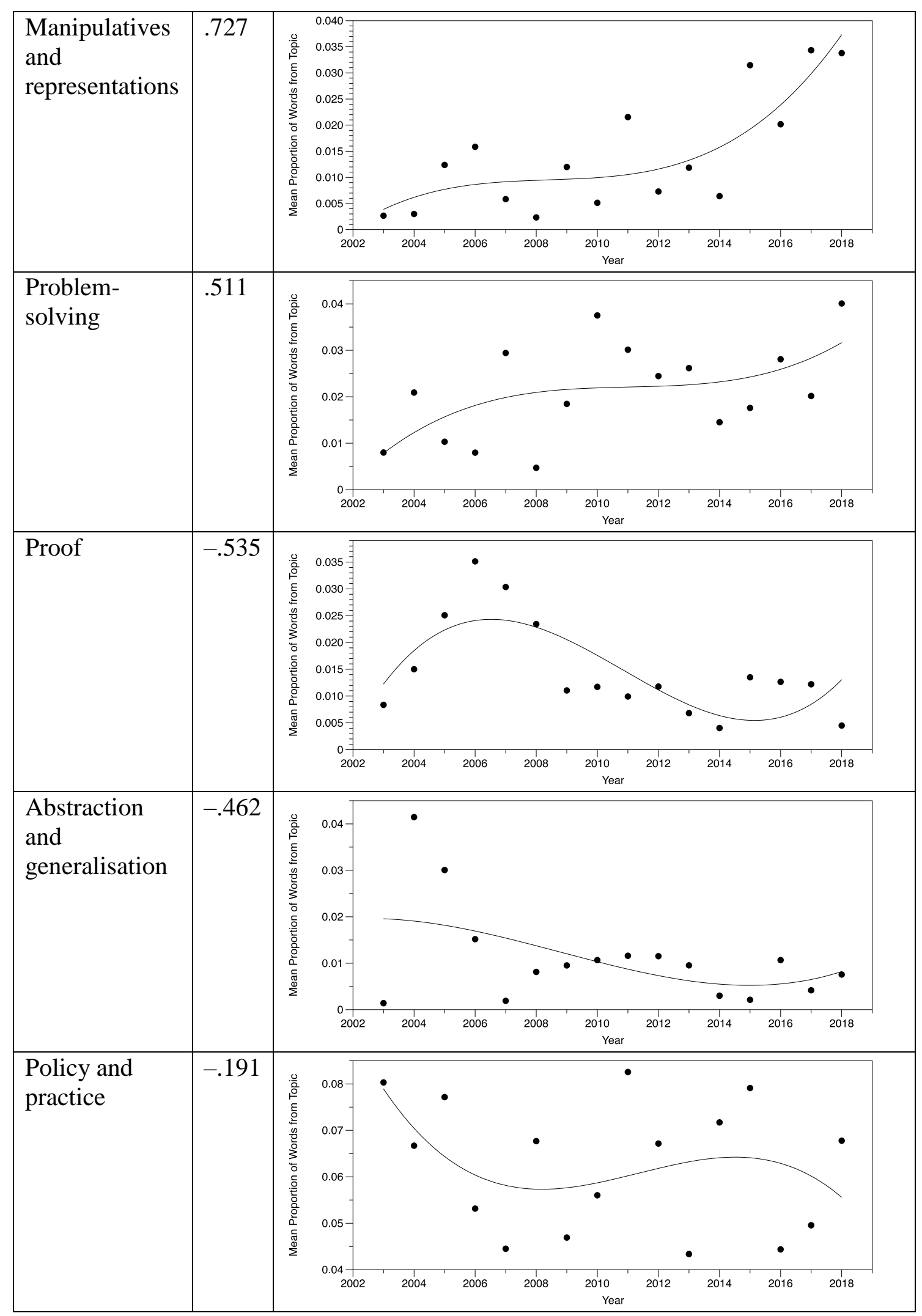




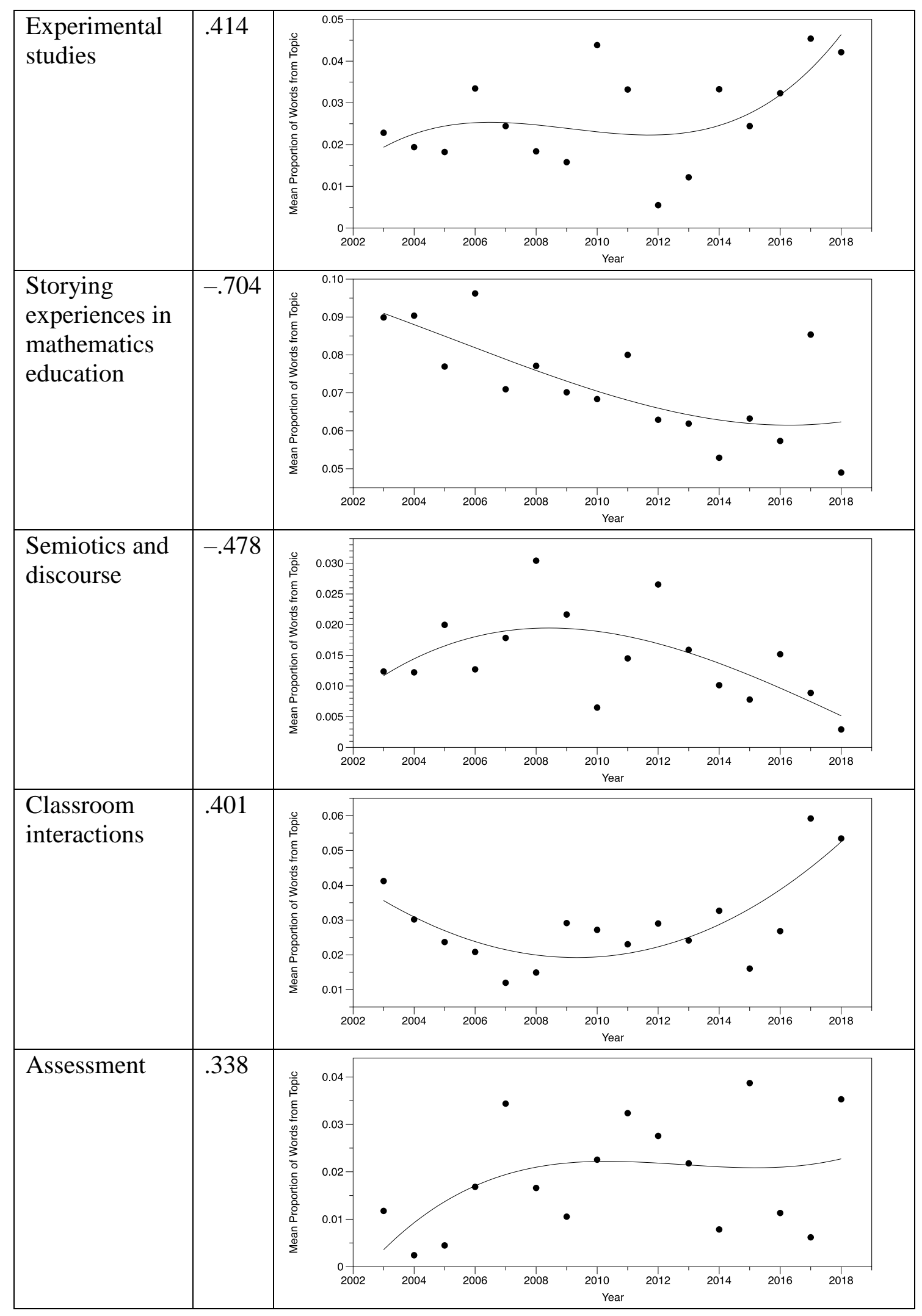




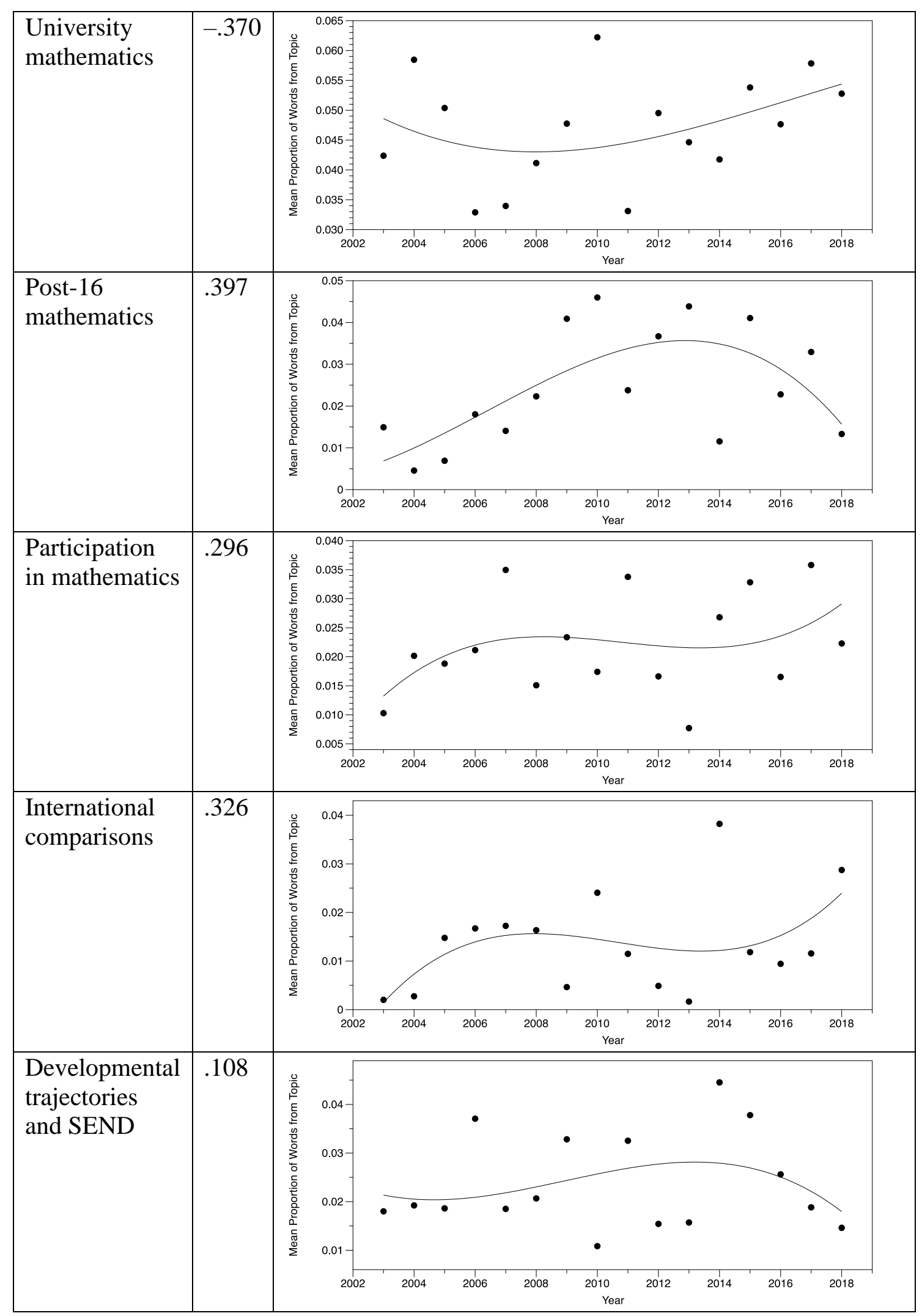

